\title{
EDUCAÇÃO A DISTÂNCIA E TUTORIA: UMA ANÁLISE A PARTIR DAS INTERAÇÕES DO TUTOR COM O PROFESSOR-FORMADOR E COM O PROFESSOR-CURSISTA
}

\author{
(DISTANCE EDUCATION AND ONLINE TUTORIALS: \\ AN ANALYSIS OF THE INTERACTIONS BETWEEN THE \\ TUTORIAL-TEACHER AND THE STUDENT TRAINEE )
}

Adriana Aparecida de Lima Terçariol

Universidade do Oeste Paulista (UNOESTE), Brasil

Universidade Nove de Julho (UNINOVE), Brasil

Raquel Rosan Christino Gitahy

Marilucia Ricieri

Universidade do Oeste Paulista (UNOESTE), Brasil

\section{RESUMO}

A Educação a Distância encontra-se em crescimento e os profissionais envolvidos no processo precisam capacitar-se para acompanhar a evolução da tecnologia e da metodologia do ensino. Entre esses profissionais, encontra-se o professor-tutor, cujas funções são orientar, estimular, motivar e construir com o aluno sua trajetória de aprendizagem. Nessa perspectiva, a presente pesquisa teve como objetivo conhecer como o curso denominado "Formação de Tutores" prepara o participante para "ser tutor"; e a segunda situação consistiu em pesquisar como foi a atuação desses tutores, enquanto mediadores e orientadores no curso "Tecnologia Assistiva $-4^{\text {a }}$ ed." da Universidade Estadual Paulista, em parceria com a Universidade Aberta do Brasil, na modalidade da Educação a Distância. Definiu-se a pesquisa de acordo com os conceitos da abordagem qualitativa. Inicialmente, foi realizada uma revisão bibliográfica e, posteriormente, foram realizadas entrevistas semiestruturadas com quatro tutores que realizaram o curso de formação e atuaram no curso "Tecnologia Assistiva". Complementando a coleta dos dados, recorreu-se à análise dos materiais pedagógicos, bem como a apreciação das interações e mediações ocorridas entre professor-formador e tutores, e tutores e professores-cursistas nos fóruns e demais ferramentas do Ambiente Virtual de Aprendizagem (AVA). A análise das informações e dos dados obtidos possibilitou identificar que os tutores se capacitaram e se prepararam para cumprir de forma adequada e eficaz as atividades de ensinar, mediar e orientar os professores-cursistas. Quanto às categorias de comportamento, consideradas na análise: identificar problemas, dar feedback, ter autonomia e promover a interação, percebeu-se que identificar problemas, promover interação e dar feedback foram assinalados nas interações entre tutor-cursista e tutor-formador nos registros dos fóruns e chats do ambiente virtual de aprendizagem, identificou-se ainda que os tutores agiram com autonomia durante sua atuação no curso de Tecnologia Assistiva. 
Palavras-chave: educação a distância, ambiente virtual de aprendizagem, formação de tutores, atuação do tutor, mediação pedagógica.

\begin{abstract}
Distance education is growing rapidly and professionals involved in this process need to empower themselves to keep pace with technology developments and new teaching methodologies. Among such teaching professionals, we can also find the teacher-tutor i.e. the person whose role it is to guide, encourage, motivate, and help build students develop their careers as well as maximize their learning. Within this perspective, this paper aims to highlight how the course titled "Training Tutors" prepares participants to become a "tutor". The second phase consisted of researching the performance of these tutors as facilitators and mentors in the course "Assistive Technology -. 4th edition", which was held at the Universidade Estadual Paulista in conjunction with the Open University of Brazil, i.e. in the distance education format. Research in this case is defined according to the concepts of the qualitative approach to teaching. Initially, we prepared a literature review, which was followed by semi-structured interviews consisting of four tutors, namely those individuals who completed the training course and who participated in the course titled: "Assistive Technology". In addition to the data collection, we analyzed the teaching materials and the feedback from the interactions and mediations between the tutorial trainers (experts) and trainee teachers (professors), and the tutors and the trainees (students), i.e. in forums and in other Virtual Learning Environment (VLE) activities. The analysis of the information and data shows that trainees were sufficiently trained and prepared to perform adequately and effectively the activities of: teaching, mediation, guidance, and training. With regard to the types of behavior considered in the analysis, it was considered important for all trainees to: identify problems, provide feedback, be autonomous, and promote interaction. Identifying problems, promoting interaction and providing feedback were reported as being essential in the interactions between the tutor and the trainee, especially in forums and chats in the virtual learning environment, although it was observed that the tutors acted somewhat autonomously during the Assistive Technology course.
\end{abstract}

Keywords: distance education, virtual learning environment, training of tutors, acting tutor, pedagogical mediation.

A Educação a Distância (EaD) não é uma forma nova de educação, mas vem, ao longo da história, passando por mudanças, reformulações e inovações em uma velocidade que impressiona. Por esta razão, trabalhar com EaD requer dos profissionais agilidade, predisposição ao que é novo. Nesse contexto, Moran (2011, p. 47) considera que: "é importante que os cursos de hoje - principalmente os de formação - sejam focados na construção do conhecimento e na interação, no equilíbrio entre o individual e o grupal, entre o conteúdo e interação”.

Sobre essa interação, Formiga e Litto (2009, p. 67) propõem que "éa interação com pessoas ou com objetos mediados por pessoas que permite a assimilação gradativa e crescente do mundo que nos rodeia [...]”. Assim, a construção do conhecimento está relacionada à "qualidade da interação conforme proposto por Piaget (1978), que, 
por sua vez, depende de mediação de outras pessoas e do próprio conhecimento do aprendiz, de acordo com Vygotsky (1978)" (Formiga e Litto, 2009, p. 67).

Nesse sentido, Moran, Masseto e Behrens (2011) mencionam que cada vez mais os alunos, e as pessoas de modo geral, têm mais acesso às informações, aos dados, vídeos. Com o auxílio da tecnologia, pode-se conseguir dados e imagens de forma rápida e atraente, transformando o papel do professor para ajudar o aluno a interpretar os dados, contextualizá-los e relacioná-los.

Moran (2011) aponta que o professor com acesso a tecnologias temáticas pode se tornar um orientador/gestor setorial do processo de aprendizagem, integrando de forma equilibrada a orientação intelectual, a emocional e a gerencial. Conforme explicitado por Moran (2011), as funções que o professor pode assumir se multiplicam com a educação mediada pela tecnologia, e entre essas está o importante papel de tutor - a distância ou presencial ou mediador, de acordo com algumas nomenclaturas que são encontradas na literatura. Como educar é uma função humana, por mais que aparatos tecnológicos estejam à disposição da educação, é fundamental a figura do professor atuando como tutor para a efetivação e legitimação do processo de Ensino a Distância.

Nesse sentido, reforça-se, aqui, a importância do profissional tutor na $\mathrm{EaD}$, bem como a necessidade da formação continuada por parte deste profissional.

\section{O TRABALHO DA TUTORIA NA EDUCAÇÃO A DISTÂNCIA}

A atividade dos professores que atuam como tutores a distância requer habilidades como empatia e capacidade para entender as personalidades de seus alunos, mesmo quando filtradas pelas comunicações transmitidas tecnologicamente, e para orientar os alunos a se envolverem ativamente no processo de aprendizado. Moore e Kearsley (2010) descrevem três funções específicas para os instrutores (denominação que Michael Moore dá para professores que atuam como tutores), a saber: função de ensino, progresso do aluno e apoio ao aluno.

Na função de ensino, a tarefa do instrutor é ressaltar as partes fundamentais do conteúdo que está sendo apresentado e discutido, intervir para orientar a discussão e interagir com os participantes - individualmente ou em grupos. Na segunda função - do progresso do aluno - o instrutor deve analisar a tarefa normal de um aluno, avaliar e comunicar cada aluno sobre o seu desempenho.

Quanto à terceira função - de apoio ao aluno - diz respeito a atender, responder ou encaminhar as dúvidas e perguntas a outro profissional (Moore e Kearsley, 2010, p. 149, grifos nossos). 
A organização da atuação pedagógica do tutor, com foco na mediação do processo de ensino e aprendizagem, é fundamental para orientar, incentivar e instigar o aluno a buscar mais conhecimento por meio de práticas individuais e coletivas. O bom relacionamento com o aluno o incentiva a fazer uso das novas tecnologias de informação e comunicação, além de apoiá-lo, oferecer suporte e auxiliar na utilização dos meios para o ensino.

Na visão de Silva Gomes de Oliveira (2007, p. 75), a Educação a Distância mantém a relação triádica que existe em todo o processo de ensino e aprendizagem, em que: "Um vértice é constituído pelo aluno, outro pelo professor-tutor e o terceiro pelo objeto do conhecimento, ou seja, os conceitos a serem construídos [...]”. O tutor, inserido nesse processo, acompanha o aluno, orienta, incentiva a aprendizagem, objetivando despertar nesse aluno o interesse pela busca do conhecimento e a melhoria no seu processo de aprendizagem.

Bentes (2009) explica que é imprescindível ao tutor incorporar a tecnologia em sua atuação, é preciso que ele tenha uma responsabilidade para com o aluno, porque não existe a possibilidade de improvisar no EAD. O autor complementa que, na EAD, sobressaem a valorização do aprender cooperativo e a disseminação do conhecimento potencializada pela tecnologia, e que isso impacta diretamente no papel do professor e do tutor.

Moran, Masseto e Behrens (2011), sobre o papel do professor na atuação como tutor, esclarecem que este necessita ser, fundamentalmente, de orientador/ mediador. Silva (2011) corrobora, nesse sentido, e compartilha com os leitores, em sua obra Criar e professorar um curso on-line, a experiência obtida ao atuar como professor-tutor de um curso on-line descrevendo que, "no ciberespaço, o professor precisa ser mais interlocutor do que um tutor, no sentido de proteger e defender alguém como guardião da instrução do aprendiz" (Silva, 2011, p. 73).

Dependendo de fatores administrativos, da estrutura dos cursos ofertados e das políticas internas de educação da instituição, o professor que atua como tutor pode interagir com o conteúdo dos cursos de diversas maneiras, tais como: fazendo comentários a respeito do conteúdo, "sugerindo fontes de consulta, propondo atividades, adicionando recursos e modificando o currículo e o próprio material do curso" (Mattar, 2009, p. 117).

Autoras como Emerenciano, Souza e Freitas (2001) descrevem a atuação do tutor e a importância de seu papel na EAD. Apontam características que são essenciais para o tutor desempenhar o seu papel de interação, orientação, mediação, adequadamente, assumindo a visão de professor-tutor. Os autores descrevem ainda que é importante ter clareza do termo "tutor" e procuram dar um significado que abrange a função importante do professor e educador: "Muitas vezes o termo é 
utilizado de forma natural sem uma ressignificação. O movimento de ressignificação deve superar a ideia do tutor como aquele que ampara, protege, defende, dirige ou que tutela alguém [...] trabalhar como tutor significa ser professor e educador" (Emerenciano, Souza e Freitas, 2001, p. 7).

Belloni (2006) descreve que as funções do tutor estão relacionadas à orientação dos alunos no estudo de disciplinas pelas quais o tutor é responsável, bem como ao esclarecimento das dúvidas, explicações referentes aos conteúdos das disciplinas e participação das atividades de avaliação. Além disso, Belloni (2006, p. 80) destaca que: "A função de orientação e conselho do processo de aprendizagem passa a ser exercida não mais em contatos pessoais e coletivos em sala de aula ou atendimento individual, mas em atividades de tutoria a distância, em geral individualizada, mediatizada através de diversos meios acessíveis”. Essa descrição de Belloni vai ao encontro das responsabilidades e papéis apresentados no Tutorial de EAD do The Commonwealth of Learning.

Emerenciano, Souza e Freitas (2001, p. 11) apontam que para o tutor atuar é fundamental estabelecer uma relação junto aos alunos que "preze pelo clima cordial, humano, provocador (problematizador), que auxilie nas dúvidas, no processo de aprendizagem e analise e responda aos trabalhos acadêmicos realizados, sempre motivando a clientela do curso".

Concluindo esta etapa da apresentação dos referenciais teóricos, a seguir serão descritos os passos da trajetória metodológica utilizada para a realização da pesquisa.

\section{PROCEDIMENTOS METODOLÓGICOS}

A presente pesquisa iniciou com o contato efetuado com a coordenação geral do curso de Tecnologia Assistiva, Projetos e Acessibilidade: Promovendo a Inclusão $-4^{\text {a }}$ ed., realizado pela Universidade Estadual Paulista - Júlio de Mesquita Filho - UNESP, em Presidente Prudente - SP. O primeiro contato teve o cunho de identificar a possibilidade de realizar uma pesquisa com tutores que receberam alguma capacitação para atuar na função, mas que estivessem atuando e exercendo a função de tutoria na Educação a Distância.

A UNESP de Presidente Prudente oferece o curso de capacitação para tutores denominada de "Formação de Tutores" e uma atualização com frequência anual, para capacitar tutores e selecionar esses profissionais para atuarem na função, mediando, interagindo, orientando os alunos no curso de Tecnologia Assistiva, Projetos e Acessibilidade: Promovendo a Inclusão (TA). Ambos os cursos - Formação de Tutores e Tecnologia Assistiva - ocorrem na sua totalidade a distância e utilizam o Ambiente Virtual de Aprendizagem AVA - TelEduc ${ }^{1}$. 
Portanto, serão apresentados neste artigo os resultados da pesquisa obtidos, por meio da recolha dos dados que estavam registrados e armazenados no Ambiente Virtual de Aprendizagem (AVA) TelEduc da Unesp, bem como das entrevistas realizadas com os tutores. A análise dos resultados foi realizada levando-se em conta a triangulação pertinente às pesquisas qualitativas, que compreende as três pontas: os objetivos traçados, os dados coletados e a teoria que a fundamentou. Foram integradas as interações registradas nos fóruns, chats e diário de bordo do AVA TelEduc com as informações obtidas por meio das entrevistas realizadas com os tutores.

Outro fator que norteou a análise e a discussão dos resultados baseou-se nas categorias dos comportamentos: identificar problemas, dar feedback, ter autonomia e promover a interação. As informações foram obtidas por intermédio das interações do tutor com o professor-formador durante o curso de Formação de Tutores e no ambiente da equipe, e nas interações do tutor com o professor-cursista, no curso de Tecnologia Assistiva $-4^{\text {a }}$ ed.

Procurou-se identificar como o tutor se considerou preparado para assumir a condução da turma de alunos-cursistas no curso de Tecnologia Assistiva $4^{\mathrm{a}}$ ed. Essas considerações foram possíveis de se obter através de algumas perguntas efetuadas na entrevista e por meio das interações registradas no AVA. Todas essas informações e análise dos resultados serão apresentadas a seguir.

\section{DESCRIÇÃO E ANÁLISE DOS RESULTADOS}

Para realizar a apresentação dos resultados e sua análise, identificou-se a importância de resgatar o objetivo proposto inicialmente, que direcionou o foco da pesquisa, a saber: o objetivo desta pesquisa consiste em investigar como ocorreram a formação e a atuação dos tutores quanto às ações de tutoria: dar feedback, identificar problemas, promover interações e ter autonomia, durante a realização de dois cursos promovidos pela Universidade Estadual Paulista Júlio de Mesquita Filho - Unesp.

Para fins didáticos, os resultados de cada categoria de ações de tutoria são apresentados com os fragmentos dos ambientes virtuais, os comentários recolhidos nas entrevistas, as discussões e os referenciais teóricos.

\section{Identificar problemas}

Tendo como referência a definição da equipe de responsáveis pela formação (2011), identificar problemas refere-se a perceber a falta de acesso ao ambiente, à dificuldade de entender a dinâmica do curso ou de usar o ambiente, e a propor soluções, criando até, se necessário, um passo a passo. 
Esse comportamento é fundamental na atuação do tutor porque, muitas vezes, o aluno não está familiarizado com o ambiente virtual ou não se adaptou à metodologia da $\mathrm{EAD}$ e acaba se afastando das atividades e das obrigações por falta de conhecimento ou habilidade, não acessando o ambiente virtual e isolando-se dos grupos.

Nesse sentido, compete ao tutor estar atento ao movimento do aluno por meio dos registros nos fóruns, observando a frequência de acesso e a forma de participação - postou comentários após ler o que os demais alunos já postaram, contribuiu com sugestões, postou algum comentário demonstrando que não está acompanhando as discussões já construídas no fórum ou acessou o fórum e apenas postou um olá aos colegas de curso. O tutor também pode identificar problemas de acesso do aluno através do chat, ou sala de bate-papo, considerado como um recurso síncrono da EAD que proporciona a interação entre alunos e tutores, ou seja, possibilita que aquele momento de discussão seja em tempo real. Uma vantagem importante para a EAD é que tanto os recursos síncronos quanto os assíncronos ficam registrados no AVA.

Nesse sentido, os autores corroboram com a ideia de que é fundamental o tutor identificar problemas que possam advir no ambiente virtual por consequência de alguma inabilidade do aluno, inoperância do sistema, dúvidas sobre o conteúdo e outras dificuldades comuns a esse ambiente.

Sobre as evidências do comportamento definido como "identificar problemas", houve ênfase nos comentários de $\mathrm{T} 1$ e $\mathrm{F}_{1}^{2}$ apresentados nos fragmentos 1 e 2.

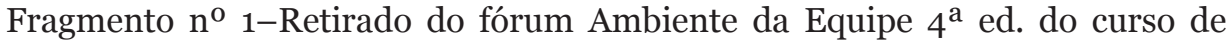
Tecnologia Assistiva $4^{\text {a }}$ ed. - T1.

T1: Estamos substituindo alguns cursistas e tem o caso daqueles que não cumpriram a proposta da agenda 1. Minha dúvida é a seguinte: Que estratégias vocês usarão para estas pessoas fazerem as atividades atrasadas? Por exemplo, o fórum... Parece que não faz muito sentido discutirem no fórum depois que a agenda já acabou... E se pedíssemos um texto sobre o vídeo A fuga das galinhas? O que acham? Beijos, T1.

T1: Os cursistas estão adorando os OAs. Em relação às atividades, não gostei da forma como a maioria tem feito o diário de bordo (não está nada reflexivo). Como combinamos, enviei um e-mail fazendo algumas considerações. Ontem enviei um e-mail cobrando os atrasados... Eles devem responder por estes dias. Beijos, T1.

F1: Olá T1, esse é mesmo o caminho, vamos aguardar as respostas dos cursistas no prazo que estabeleceu a eles, abraços, F1. 
No ambiente de Formação da Equipe, também foi identificado esse comportamento em um comentário da tutora $\mathrm{T} 4$ :

Fragmento $\mathrm{n}^{\mathrm{o}}$ 2-Retirado do fórum Ambiente da Equipe $-4^{\mathrm{a}}$ ed. $-\mathrm{T} 4$.

T4: Olá, F4, tenho cinco cursistas que ainda não fizeram acesso ao ambiente ou apenas uma vez. Tentei ligar, mas não deu certo, não atenderam. Mandei então e-mail para seus endereços pessoais... vamos esperar. Dei um prazo até domingo às $12 \mathrm{~h}$ para acessarem ou perderão a vaga. Aos que apenas participaram uma vez do fórum ou outra atividade, enviei um e-mail pelo correio interno do ambiente, chamei a todos os cursistas, inclusive aos ativos e participativos, pedi para cada um me ajudar a incentivar o colega a participar. Será que fiz certo? Vamos ver os resultados. Até! T4.

Diante dos dados aqui apresentados, pode-se apontar que houve evidências do comportamento "identificar problemas" nas interações entre tutor e cursista no curso de TA e entre professor-formador e tutor no ambiente virtual do curso de Formação de Tutores. Isso corrobora com a pesquisa no sentido de que é um comportamento inerente à função do tutor e que pode contribuir para a aprendizagem na educação a distância.

\section{Promover interações}

O comportamento denominado "promover interações" pode ser descrito como o estímulo que o tutor ou formador proporciona aos cursistas para que se relacionem com os demais cursistas e associem a atividade teórica com a prática. Maia e Mattar (2007, p. 92) asseveram que o promover interação é uma função considerada pedagógica e intelectual atribuída ao tutor e que contempla o "incentivar a pesquisa, fazer perguntas, coordenar as discussões, sintetizar seus pontos principais e desenvolver o clima intelectual geral do curso, encorajando a construção do conhecimento". Foram identificadas essas atribuições e ações apontadas por Maia e Mattar descritas de forma clara e explicativa para os tutores e formadores.

Pode-se verificar que as interações facilitam na atuação e no desempenho da função do tutor. Essa questão importante, exposta por Almeida, foi identificada no trecho da entrevista com a tutora F4: "saber mediar é fundamental principalmente quando se trata de fóruns e chats. A interferência do tutor é importante para que os alunos não percam o foco nessas ferramentas". De acordo com Almeida (2011), tratase de um papel significativo na Educação a Distância. É possível verificar evidências por meio de trechos das entrevistas realizadas com as tutoras e fragmentos retirados dos fóruns do curso de Formação e do curso de TA, ou seja, entre tutor e professorformador, e do tutor com o professor-cursista. 
As respostas das tutoras sobre a questão "Descreva quais foram os fatores identificados como facilitadores da sua atuação enquanto tutor” são:

O apoio da equipe, ter uma formadora responsável em constante interação (T1).

Tive constante acompanhamento de minha formadora, tirando todas as minhas dúvidas... Consegui me entrosar bem com a turma, adquirindo confiança dos alunos. Trabalho com alunos com deficiência, assim pude trocar ideias bem práticas e realistas com minhas alunas, além do que eles passam todo o conteúdo do curso, como agendas, textos e programas, assim eu só complementava com o material que já tinha. O ambiente virtual é também muito fácil e claro para navegar, os alunos pegam o jeito rapidinho (T2).

A interação entre toda a equipe, sempre podia contar com os demais do grupo, minha formadora, a conteudista, secretária, todos sempre dispostos a ajudar, o ambiente também, pelo fácil acesso (T3).

Troca de experiências com outros tutores e os próprios alunos do curso... o curso de formação pode contribuir bastante para a atuação do tutor, um ajuda o outro, e também tem os bate-papos entre a equipe, como uma espécie de formação contínua (T4).

Leite e Tassoni (2012) asseveram sobre a essencialidade da mediação ao discorrerem que:

A qualidade da mediação determina toda a história futura da relação entre o aluno e um determinado conteúdo ou prática desenvolvida na escola. Os educadores que desenvolvem uma mediação afetiva com resultados afetivos determinam processos de constituições individuais duradouros e importantes para os indivíduos (p. 13).

São encontradas referências sobre os resultados da mediação pautada na relação afetiva durante o diálogo entre T1 e uma cursista:

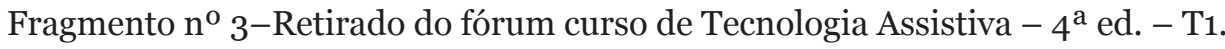


T1: Olá queridos! Com o objetivo de trocarmos mensagens para nos despedir e também para criar um espaço em que vocês possam ficar à vontade, para colocar a importância que esse curso teve na vida de cada um, seja profissional ou pessoalmente falando, criamos esse fórum. Não é uma atividade do curso, por isso a participação não é obrigatória, mas sim voluntária. Estamos felizes porque mais uma etapa se cumpriu, mas ao mesmo tempo tristes, porque sentiremos falta de vocês... Mas, aproveitamos desde já para desejar muito sucesso e felicidades a todos vocês! Aguardamos vocês para nosso último Bate-Papo, nosso "Baile de Formatura Virtual” que será na quinta-feira, 07/07 às 20h pela Sala Virtual. Abraços calorosos. T1

CS: Apesar desse curso ser mui trabalhoso, já estou sentindo saudades. Eu, particularmente, aprendi muito, não só conhecimentos que serão inseridos na minha prática pedagógica, mas, na minha vida mesmo. Principalmente... a observar a opinião das outras pessoas, a aprender, a pesquisar, a querer ser diferente e não ser melhor. Aprendi a ser mais curiosa, a deixar minhas aulas mais interativas... Bem... acho que meus alunos que saíram ganhando depois deste curso que fiz, rsrss. Qualquer curso novo que souberem, me comuniquem. CS.

Ao discutir sobre a interação, Moran argumenta que:

É fundamental procurar estabelecer, desde o início, uma relação empática com os alunos, procurando conhecê-los, fazendo um mapeamento dos seus interesses, formação e perspectivas. A preocupação com os alunos - a forma de nos relacionarmos com eles - é imprescindível para o sucesso pedagógico (2011, p. 44).

Nesse sentido, Masseto (2011) elucida a questão da interação como sendo uma ação fundamental do processo de ensino e aprendizagem, ao dizer que:

[...] o aprendiz é o centro desse processo e em função dele e de seu desenvolvimento é que precisará definir e planejar ações. Essa concepção de aprendizagem há que ser vivida e praticada. Trata-se de uma ação contínua sua e de seus alunos, sabendo esperar, compartilhar, construir juntos. Entender e viver a aprendizagem como interaprendizagem (p. 168).

Essas explanações de Masseto e Moran foram evidenciadas durante os cursos de formação e Tecnologia Assistiva. Corrobora com essas afirmativas o trecho da entrevista com a tutora T2: "consegui me entrosar bem com a turma, adquirindo confiança dos alunos". Foram encontrados em T1 comentários que complementam a questão em discussão: "penso que as propostas reflexivas (principalmente as do diário de bordo) levam o professor a se questionar, refletir sobre sua prática. A partilha no fórum também é fundamental" (T1).

Considerando as categorias de comportamento que nortearam a pesquisa, a seguir abordamos uma habilidade que pode ser considerada como essencial nos processos de comunicação e de ensino e aprendizagem, que é o feedback. 


\section{Dar feedback nas atividades}

Masseto (2011, p. 164) descreve feedback como sendo "um processo de retroalimentação que traz ao aprendiz informações necessárias, oportunas e no momento em que ele precisa para que desenvolva sua aprendizagem". Nesse sentido, vale a pena ressaltar como a categoria relativa a dar feedback é importante e considerada como uma retroalimentação do processo de ensino e aprendizagem. Para o cursista, é fundamental saber sobre seu desempenho e comportamento no ambiente virtual; para o tutor, o feedback é essencial para corrigir possíveis falhas e adequar a metodologia e as práticas no ensino; e, para o professor-formador, considera-se primordial, como fator de aprimoramento dos conteúdos e da metodologia para próximas formações, e também na atuação, com o propósito de melhoria contínua desse processo.

É possível confirmar a existência dessa prática nos cursos pesquisados pelas menções das tutoras durante a entrevista e pelos fragmentos dos diálogos resgatados no ambiente virtual de aprendizagem, conforme citação de T1: "um ponto importante que caracteriza a atuação do tutor é dar feedback rápido ao cursista, e ser reflexivo".

Comentário de T2 sobre feedback:

A prática foi muito significativa durante o curso. E a partir de nossas respostas, as coordenadoras faziam críticas construtivas. Tínhamos reuniões com as coordenadoras periodicamente, uma vez por semana, tanto no curso de formação, como no curso de TA, virtual com áudio, no ambiente da equipe e durante a formação, no ambiente da formação (T2).

Sobre o feedback proporcionado nos cursos que ocorrem na Educação a Distância, Masseto (2011, pp. 165-166) considera que:

A informação em forma de feedback pode vir de outro colega ou de outro grupo que analisa atividades de outro colega ou de outro grupo e eles se oferecem feedback mutuamente. São informações necessárias oferecidas ao longo de todo o processo de aprendizagem, não somente em momentos como avaliação de conteúdo. Deve ocorrer de forma contínua para que o aprendiz vá adquirindo consciência de seu avançar em direção aos objetivos propostos, e de seus erros e falhas que precisarão ser corrigidos imediatamente [...] o feedback que mediatiza a aprendizagem é aquele colocado de forma clara, direta, por vezes orientado discursivamente, por vezes por meio de perguntas, ou de uma breve indicação ou sugestão.

Quanto ao feedback praticado durante o curso de formação para tutores, pode-se evidenciar sua importância por meio do comentário que a tutora $\mathrm{T} 4$ fez no momento da entrevista: 
[...] é por meio do curso que o futuro tutor vai se familiarizar com o AVA, com a dinâmica do curso, criar algumas estratégias, pois no curso eles colocam alguns estudos de caso, de como lidar com situações com os cursistas, como corrigir e dar feedbacks. Na Unesp eles priorizam muito os feedbacks, em todas as atividades devemos escrever os feedbacks. Mas nós, formandos, temos que criar nossos próprios feedbacks, é um treino (T4).

Abreu-e-Lima e Alves, em artigo, escrevem que a tarefa do tutor é bastante desafiadora e complexa, por isso precisa ser orientada e ter apoio da equipe de formadores por meio de feedback. Os autores salientam, ainda, que:

A formação especializada da equipe de tutores é fundamental para que a proposta de EAD de uma instituição possa ser implementada a contento [...] uma das interações existentes no processo de ensino e aprendizagem é o processo de feedback entre tutor e estudante [...] sem feedback os participantes não têm consciência de qual é o conteúdo específico em que devem investir mais seu tempo ou, ainda, não podem saber o que já conseguem fazer benfeito, para que possam manter ou repetir o comportamento ou a atitude adotados (2011, p. 194).

No diário de bordo, as tutoras T2 e T3 dão feedback às cursistas a respeito das suas reflexões sobre o texto lido e das superações alcançadas após passar o momento inicial de adaptação ao Ambiente Virtual de Aprendizagem do curso de TA. Vejamos os fragmentos 4 e 5 :

Fragmento ${ }^{0}$ 4-Retirado do Diário de Bordo - Ambiente do curso de Tecnologia Assistiva $4^{\mathrm{a}}$ ed. - T2.

T2: Olá, CS! Você conseguiu extrair do texto dados que farão diferença em sua vida, e vejo que já está colocando-os em prática. Esse texto é ótimo e depende de nós, com "um pouco de esforço e determinação", fazer com que nossos objetivos sejam alcançados. T2

Fragmento ${ }^{0}{ }^{5}$-Retirado do Diário de Bordo - Ambiente do curso de Tecnologia Assistiva $4^{\mathrm{a}}$ ed. $-\mathrm{T} 3$.

CS: Na primeira semana de curso não foi nada fácil, pois tive dificuldades em acessar as atividades corretamente e postar minhas atividades em páginas corretas, atrapalhada como é de se esperar nos primeiros dias de conhecimento das ferramentas. $\mathrm{O}$ curso nos oferece ferramentas e interação valiosas para enriquecer nossos conhecimentos. Tive muita ajuda das colegas do meu grupo e também do tutor e formadora, auxiliando nas dúvidas e nas postagens que fiz erradas. Pude explorar bastante o ambiente me familiarizando melhor com as ferramentas e assim podendo participar melhor do curso. Foram momentos de adaptações dos recursos e das trocas. Muito ricas!!!!

T3: Olá CS, que bom ver seus relatos de superação, e de que está mais familiarizada com o ambiente. Com certeza você irá muito bem neste módulo assim como foi no anterior. Beijos. 
É preciso que tutores, professores, formadores e equipes envolvidas em processos de aprendizagem se atentem à linguagem utilizada para fazer uso do feedback. Abreu-e-Lima e Alves apontam alguns cuidados básicos:

Os cuidados básicos e os papéis assumidos e transmitidos pelo tom da mensagem ou pela linguagem escolhida são alguns aspectos a que os tutores devem estar atentos, ao elaborar o feedback. Para facilitar o processo de elaboração, sugere-se considerar modelos de feedback (estruturas de mensagem em sua complexidade e extensão), seu conteúdo (verificação de erros e acertos no conteúdo da disciplina), ritmo e constância das interações (tempo e quantidade de resposta) (2011, p. 195).

De acordo com citação de Maia e Mattar (2007, p. 91), o tutor é responsável por manter um tom amigável, podendo utilizar o humor sempre que conveniente: "O tutor é responsável em gerar um senso de comunidade na turma que conduz e por isso deve ter elevado grau de inteligência interpessoal, desempenhando um papel social, e para isso deve conhecer o máximo possível seu público-alvo". O uso de linguagem afetiva diz respeito à interação afetiva que possibilita mais proximidade entre tutor e cursista, deixando-os mais à vontade para expressar suas ideias e expressar sentimentos. Evidencia-se a afetividade nos trechos das entrevistas apresentadas a seguir, cujos comentários são das tutoras T1 e T2.

A afetividade e o bom humor não podem faltar. O clima amistoso, as brincadeiras ajudam a quebrar barreiras... ser exigente, buscar a qualidade, também é fundamental feedback rápido ao cursista, ser reflexivo, gostar de escrever, ter muita paciência, intuição! Ter boa... fundamentação também. Utilizar-se de boas referências sobre o tema, sobre a área pedagógica, sobre as relações humanas (T1). (T2).
(T)

A gente tem que cobrar, mas ao mesmo tempo mostrar compreensão e carinho

Almeida (2011, p. 215) argumenta sobre a presença da afetividade e da emoção em ambientes virtuais de aprendizagem, como segue:

A imediata recuperação dos registros das interações e produções dos alunos permite revisitá-los a qualquer tempo e revela o significado do curso para a formação dos professores, conforme pequenos trechos de depoimentos reveladores de um processo de autonomia em relação à gestão da própria aprendizagem e produção de conhecimento, a importância de compartilhar saberes e sentimentos, a compreensão da articulação teoria-prática e a presença da afetividade e da emoção valorizando o respeito mútuo e a melhoria da autoestima.

O fragmento 6, referente ao feedback de uma cursista, corrobora com várias questões que foram aqui apresentadas e discutidas: os resultados que podem ser obtidos na EAD praticando no processo ensino e aprendizagem a interação entre os personagens envolvidos, a importância da afetividade nas relações e mediações, e as 
contribuições que se alcançam quando o processo de feedback é aplicado de forma efetiva. Podemos evidenciar essas conjecturas no fragmento a seguir:

Fragmento n ${ }^{0}$ 6-Retirado do fórum do curso de TA - $4^{\mathrm{a}}$ ed. - Cursista e T2.

T2: Achei "demais" esse comentário no fórum! Sinal que o curso está alcançando seus objetivos.

CS: Gente, acabei de ler o texto complementar "Introdução à Tecnologia Assistiva" e estou simplesmente maravilhada! Sei que muitas das colegas cursistas trabalham em APAEs e devem ter conhecimentos de muitos dos temas abordados no texto, mas para mim, que sempre trabalhei em escola regular e nunca tive um aluno com deficiência, é tudo muito novo! Há pouco tempo fiz o curso básico de libras e também fiquei encantada, me apaixonei e estou louca para fazer o curso intermediário e/ou avançado. Agora, após a leitura deste texto, aprendi coisas que para mim, até então, eram inimagináveis! Também não me envergonho em dizer que não conhecia a diferença entre órteses e próteses... enfim, estou cada vez mais animada e muito feliz por estar tendo esta oportunidade ímpar de aprendizagem. Tudo que aprendo adoro compartilhar com minhas colegas de trabalho, fazemos trocas valiosíssimas CS.

A utilização da linguagem afetiva nos momentos em que o tutor está interagindo com o cursista é considerada fundamental, como se pode perceber nos comentários e nas argumentações citadas. Grande parte do sucesso que se obtém na educação, principalmente a distância, está respaldada pela forma de se comunicar com respeito, com paciência e com expressão da afetividade.

\section{Ter autonomia}

Para falar desse comportamento, é resgatado o conceito apresentado por Piaget (1972) se referindo à autonomia como uma condição do agir de maneira que conduza à cooperação, não sendo o indivíduo autônomo aquele que se individualiza, mas que valoriza o respeito mútuo, a democracia, a reciprocidade, o amor e a afetividade, proporcionando campo mais fértil para aprendizagem de crianças e adultos.

Como resultado da pesquisa, o comportamento "ter autonomia" foi identificado em vários momentos e situações no ambiente virtual e nas entrevistas, evidências que corroboram que tutores e formadores valorizam a autonomia e a praticam durante sua atuação. Pode-se verificar esse assunto no fragmento retirado do ambiente do curso de TA, entre F2 e T2:

Fragmento $\mathrm{n}^{\mathrm{0}}$ 7-Retirado do fórum Ambiente do Curso de Tecnologia Assistiva $-4^{\mathrm{a}}$ ed. - T2 e F2. 
T2: Olá, F2! O bate-papo dessa semana deixarei focado na Etapa 3 do projeto. Vou marcar o bate-papo final (Formatura) para a próxima semana, onde o assunto será o encerramento do curso e o que este modificou em suas concepções e prática pedagógica. Pretendo também fazer um vídeo de despedida com as fotos das alunas e nossas também, é claro! Mas estou aceitando mais sugestões! Abraços, T2.

Evidencia-se a autonomia nos trechos das entrevistas apresentadas a seguir, cujos comentários são das tutoras T1 e T4.

Os coordenadores estão sempre dispostos a ajudar... a discutir, a fomentar reflexões... você vai clareando as ideias... em tempo real tirando dúvidas é o diferencial, em meu ponto de vista... e você tá falando com quem coordena o módulo, então ela sabe onde quer chegar... e o que tem que fazer para chegar lá (T1).

Já tinha ideia de como deveria ser a atuação do tutor no curso. Eu me baseei na minha tutora do curso, como ela agia, as respostas, o tom como tratava os cursistas, os feedbacks. A minha tutora foi a base para meu curso de formação (T4).

Conforme comentários das tutoras, o ambiente de formação e atuação dos tutores apresenta indícios de comportamentos de respeito mútuo, de ajuda, de reciprocidade entre tutores, formadores e cursistas. Identificamos interações nesse sentido no ambiente, de acordo com os fragmentos 8, 9 e 10.

Fragmento $\mathrm{n}^{\mathrm{O}}$ 8-Retirado do fórum Ambiente de Equipe do curso de Tecnologia Assistiva $-4^{\mathrm{a}}$ ed. $-\mathrm{T} 4$ e F4.

Olá, F4. Entrei em contato com os cursistas solicitando a participação no fórum "Diálogo Inicial" e a leitura do Manual do cursista. Segui os passos da nossa agenda. Estou no caminho certo??? Beijo.

Fragmento $\mathrm{n}^{\mathrm{o}}$ 9-Retirado do fórum Ambiente de Equipe do curso Tecnologia Assistiva $-4^{\mathrm{a}}$ ed. $-\mathrm{CO}$ e $\mathrm{T} 4$.

CO: Caros tutores e formadores, as atividades que se seguirão em nosso curso trilham o viés das desigualdades culturais e sociais, e exigirão reflexões aprofundadas sobre a realidade da educação por parte de todos nós. No desenrolar dos nossos trabalhos, devemos nos dar a oportunidade de nos conhecermos melhor, de nos encantarmos com a temática e com a possibilidade, mesmo a distância, de nos aproximarmos um pouco mais uns dos outros. Daí a importância de mantermos esse ambiente habitado pelo respeito, pela cortesia e pelo carinho. Bom trabalho a todos, abraços fraternos - CO.

T4: Boa noite, CO. Tenho certeza de que aprenderemos muito juntos. Estou ansiosa por essa nova experiência de ensino. Grande abraço. T4. 
Fragmento $\mathrm{n}^{\mathrm{o}} 10$ - Retirado do fórum Ambiente do Curso de Tecnologia Assistiva $-4^{\mathrm{a}}$ ed. $-\mathrm{T} 4$ e F4.

T4: Olá, F4, Tenho cinco cursistas que ainda não fizeram acesso ao ambiente ou apenas uma vez. Tentei ligar mas não deu certo, não atenderam. Mandei então e-mail para seus endereços pessoais... vamos esperar. Dei um prazo até domingo às $12 \mathrm{~h}$ para acessarem ou perderão a vaga. Aos que apenas participaram uma vez do fórum ou outra atividade, enviei um e-mail pelo correio interno do ambiente, chamei a todos os cursistas, inclusive aos ativos e participativos, pedi para cada um me ajudar a incentivar o colega a participar. Será que fiz certo? Vamos ver os resultados. Até! T4.

F4: Vc está certa. Enviei um e-mail para todas as minhas tutoras dizendo que se não acessaram ou não fizeram as atividades sem justificativa devem ser substituídos imediatamente. F4.

Tendo em vista os resultados apresentados, validados com citações das tutoras entrevistadas e dos fragmentos das interações obtidas no ambiente virtual, e a complementação com os referenciais teóricos, pode-se concluir que, durante o curso de Formação de Tutores e de Tecnologia Assistiva $4^{\mathrm{a}}$ ed., encontramos evidências das categorias de comportamento como: identificação de problemas, promoção de interação, dar feedback e ter autonomia nas interações entre professor-formador e tutor e, entre tutor e professor-cursista. Este fato leva a crer que, dentre muitos comportamentos que podem indicar resultados satisfatórios na educação a distância mediada pelo tutor, podem ser considerados como essenciais na atuação do tutor.

Conclui-se, também, que o curso de Formação para Tutores da Unesp preparou os tutores para atuarem no curso de Tecnologia Assistiva $4^{\mathrm{a}}$ ed. Corroborando, dessa forma, com a ideia de que o tutor tem um espaço já ocupado na Educação a Distância, e que a sua atuação, a sua postura e a sua interação no ambiente virtual podem fazer a diferença no processo de ensino e aprendizagem do aluno que optou em estudar e aprimorar-se por meio da EaD, validando a importância desse profissional se capacitar continuamente, participar de cursos de formação e reciclagem, desenvolvendo suas competências, habilidades e atitudes ao longo de sua carreira profissional. "A formação especializada da equipe de tutores é fundamental para que a proposta de EaD de uma instituição possa ser implementada a contento. Uma premissa importante neste processo de ensino-aprendizagem a distância é investir em um modelo dialógico de EaD” (Abreu-e-Lima e Alves, 2011, p. 189). 


\section{NOTAS}

1. O TelEduc é um ambiente para realização de cursos a distância por meio da Internet. Está sendo desenvolvido no Nied (Núcleo de Informática Aplicada à Educação) sob a orientação da Profa. Dra. Heloísa Vieira da Rocha do Instituto de Computação da Unicamp (Universidade Estadual de Campinas), a partir de uma metodologia de formação de professores construída com base na análise das várias experiências presenciais realizadas pelos profissionais do núcleo.

2. Neste artigo, para a identificação dos sujeitos pesquisados serão utilizadas as seguintes denominações: T1 (Tutor da turma 30); T2 (Tutor da Turma 15); T3 (Tutor da Turma 47); T4 (Tutor da Turma 37); CO (Coordenador do Curso); Fo, F1, F2, F3, F4 (Formadores); CS (Cursistas).

\section{REFERÊNCIAS BIBLIOGRÁFICAS}

Abreu-e-Lima, D. M., e Alves, M. N. (2011). O feedback e sua importância no processo de tutoria a distância. Pro-Posições, 22(2) (65), 189-205, Campinas/SP.

Almeida, M. E. B. (2011). Educação, Ambientes virtuais e interatividade. In M. Silva, (Org.), Educação on line teorias, práticas, legislação, formação corporativa (pp. 203-232). São Paulo: Loyola Jesuítas.

Belloni, M. L. (2006). Educação a Distância. 4. ed. Campinas: Autores Associados.

Bentes, R. F. (2009). A avaliação do tutor. In M. Formiga, e F. M. Litto, (Orgs.), Educação a Distância - o estado da arte (pp. 166-170). São Paulo: Pearson Education do Brasil.

Emerenciano, M. S., Souza, C. A., e Freitas, L. G. (2001). Ser Presença como Educador, Professor e Tutor.Colabor@-Revista Digital da CVA-Ricesu, 1(1), 4-11. Curitiba. Recuperado de http://www. ricesu.com.br/colabora/n1/artigos/n 1/ id02.pdf.

Formiga, M., e Litto, F. M. (Orgs.). (2009). Educação a Distância - o estado da arte. São Paulo: Pearson Education do Brasil.

Leite, S. A. S., e Tassoni, E. C. M. (2012). A afetividade em sala de aula: as condições de ensino e a mediação do professor. Recuperado de www.
fe.unicamp.br/alle/textos/SASLAAfetividadeemSaladeAula.pdf

Litto, F. M. (Coord.). (2012). Competências para educação a distância: referenciais teóricos e instrumentos para validação. ABED. Projetos Competências para a Educação a Distância. Recuperado de http://www2.abed.org.br/documentos/ ArquivoDocumento712.doc.

Maia, C., e Mattar, J. (2007). ABC da EAD: a educação a distância hoje. São Paulo: Pearson Prentice Hall.

Mattar, J. (2009). Interatividade a aprendizagem. In M. Formiga, e F. M. Litto, (Orgs.), Educação a Distância - o estado da arte (pp. 112-120). São Paulo: Pearson Education do Brasil.

Masseto, M. T. (2011). Mediação Pedagógica e o uso da tecnologia. In J. M. Moran, M.T. Masseto, e M. A. Behrens. Novas tecnologias e mediação pedagógica. (pp. 133-173). 19. ed. Campinas: Papirus.

Moore, M. G., e Kearsley, G. (2010). Educação a Distância: uma visão integrada. São Paulo: Cengage Learning.

Moran, J. M. (2011). Contribuições para uma pedagogia da educação online. In M. Silva, (Org.), Educação on-line teorias, práticas, legislação, formação corporativa (pp. 41-52). São Paulo: Loyola Jesuítas. 
Moran, J. M., Masseto, M. T., e Behrens, M. A. (2011). Novas tecnologias e mediação pedagógica. 19. ed. Campinas: Papirus.

Piaget, J. (1972). Seis estudos de Psicologia. Rio de Janeiro: Companhia Editora Forense.

Silva Gomes de Oliveira, E. (2007). Ação docente na educação à distância: competências para a mediação em rede. Revista Electrónica Teoría de la Educación. Educación y Cultura en la Sociedad de la Información, 8(2), 69-85. Recupearao de http://www.redalyc.org/ redalyc/pdf/2010/201017334005.pdf

Silva, M. (Org.). (2011). Educação on-line teorias, práticas, legislação, formação corporativa. São Paulo: Loyola Jesuítas.

\section{PERFIL ACADÊMICO E PROFISSIONAL DAS AUTORAS}

Adriana Aparecida de Lima Terçariol. Doutora em Educação e Currículo pela Pontifícia Universidade Católica de São Paulo/Brasil. Mestre e Pedagoga pela Faculdade de Ciências e Tecnologia Unesp/Campus de Presidente Prudente/ SP/Brasil. Atualmente é docente na modalidade presencial e em EaD no Curso de Pedagogia na Universidade Nove de Julho (UNINOVE-SP/Brasil). Pesquisadora e Docente no Programa de Pós-Graduação-Mestrado em Educação na Universidade do Oeste Paulista (UNOESTE-Presidente Prudente-SP/Brasil).

E-mail: atercariol@gmail.com

Raquel Rosan Christino Gitahy. Docente da Universidade Estadual do Mato Grosso do Sul e da Universidade do Oeste Paulista. Possui graduação em Pedagogia pela Universidade Estadual Paulista Júlio de Mesquita Filho (1994), graduação em Direito-Instituição Toledo de Ensino (1994), mestrado em Curso de Pós Graduação Em Educação pela Universidade Estadual Paulista Júlio de Mesquita Filho (1997) e doutorado em Curso de Pós Graduação Em Educação Área de Concentração pela Universidade Estadual Paulista Júlio de Mesquita Filho (2002).

E-mail: raquel@unoeste.br

Marilucia Ricieri. Mestre em Educação. Especialista em Psicologia Organizacional e do Trabalho. Pós- Graduada em Comportamento Organizacional. Graduação em Psicologia pela Universidade Estadual de Londrina. Docente da Faculdade Pitágoras, Consultora e Instrutora credenciada Sebrae.

E-mail:marilucia@sercomtel.com.br 
ENDEREÇO

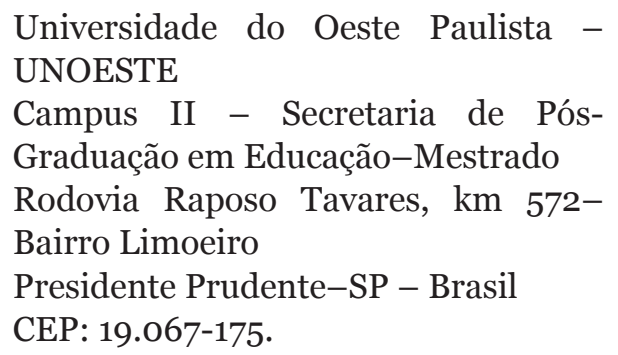

Fechas de recepción del artículo: 14/06/2014

Fecha de aceptación del artículo: 21/09/2014

\section{Como citar este artículo:}

de Lima Terçariol, A. A., Rosan Christino Gitahy, R., y Ricieri, M. (2015). Educação a distância e tutoria: uma análise a partir das interações do tutor com o professor-formador e com o professor-cursista. RIED. Revista Iberoamericana de educación a Distancia, volumen $18, \mathrm{n}^{\circ}$ 1, pp. 257-275. 